\title{
Estimating the wave 1 and wave 2 infection fatality rates from SARS-CoV-2 in India
}

\author{
Soumik Purkayastha' ${ }^{1}$, Ritoban Kundu², Ritwik Bhaduri², Daniel Barker ${ }^{1}$, Michael Kleinsasser ${ }^{1}$, \\ Debashree Ray ${ }^{3,4}$ and Bhramar Mukherjee ${ }^{1,5,6^{*}}$ (i)
}

\begin{abstract}
Objective: There has been much discussion and debate around the underreporting of COVID-19 infections and deaths in India. In this short report we first estimate the underreporting factor for infections from publicly available data released by the Indian Council of Medical Research on reported number of cases and national seroprevalence surveys. We then use a compartmental epidemiologic model to estimate the undetected number of infections and deaths, yielding estimates of the corresponding underreporting factors. We compare the serosurvey based ad hoc estimate of the infection fatality rate (IFR) with the model-based estimate. Since the first and second waves in India are intrinsically different in nature, we carry out this exercise in two periods: the first wave (April 1, 2020-January 31, 2021) and part of the second wave (February 1, 2021-May 15, 2021). The latest national seroprevalence estimate is from January 2021, and thus only relevant to our wave 1 calculations.

Results: Both wave 1 and wave 2 estimates qualitatively show that there is a large degree of "covert infections" in India, with model-based estimated underreporting factor for infections as 11.11 (95\% credible interval (Crl) 10.7111.47) and for deaths as 3.56 (95\% $\mathrm{Crl} 3.48-3.64)$ for wave 1. For wave 2, underreporting factor for infections escalate to 26.77 (95\% Crl 24.26-28.81) and to 5.77 (95\% Crl 5.34-6.15) for deaths. If we rely on only reported deaths, the IFR estimate is $0.13 \%$ for wave 1 and $0.03 \%$ for part of wave 2 . Taking underreporting of deaths into account, the IFR estimate is $0.46 \%$ for wave 1 and $0.18 \%$ for wave 2 (till May 15). Combining waves 1 and 2, as of May 15, while India reported a total of nearly 25 million cases and 270 thousand deaths, the estimated number of infections and deaths stand at 491 million (36\% of the population) and 1.21 million respectively, yielding an estimated (combined) infection fatality rate of $0.25 \%$. There is considerable variation in these estimates across Indian states. Up to date seroprevalence studies and mortality data are needed to validate these model-based estimates.
\end{abstract}

Keywords: Case fatality rate, Excess deaths, False negative rates, India, RT-PCR test, SEIR model, Underreporting

\section{Introduction}

\section{Main text}

In late August 2020, India was predicted to surpass the United States in terms of reported case counts from SARS-CoV-2 infections. To the surprise of many modelers the curve turned corner in late September

\footnotetext{
*Correspondence: bhramar@umich.edu

${ }^{1}$ Department of Biostatistics, University of Michigan, Ann Arbor, Ml 48109, USA

Full list of author information is available at the end of the article
}

with the highest number $(97,894)$ of daily new cases reported on 16 September 2020 [1]. After a steady decline for nearly five months, the curve started rising again, growing into an astronomic second wave. The highest number $(414,280)$ of daily new cases in wave 2 was reported on May 6, 2021. As of May 15, 2021, India has reported 24.7 million cases, the second highest in the world, and nearly 270 thousand deaths, the third highest in the world. In this brief report, we reconcile estimates of the infection fatality rate (IFR) inferred from seroprevalence studies with

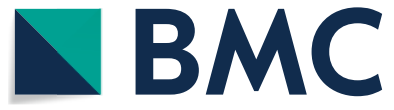

(c) The Author(s) 2021. This article is licensed under a Creative Commons Attribution 4.0 International License, which permits use, sharing, adaptation, distribution and reproduction in any medium or format, as long as you give appropriate credit to the original author(s) and the source, provide a link to the Creative Commons licence, and indicate if changes were made. The images or other third party material in this article are included in the article's Creative Commons licence, unless indicated otherwise in a credit line to the material. If material is not included in the article's Creative Commons licence and your intended use is not permitted by statutory regulation or exceeds the permitted use, you will need to obtain permission directly from the copyright holder. To view a copy of this licence, visit http://creativeco mmons.org/licenses/by/4.0/. The Creative Commons Public Domain Dedication waiver (http://creativecommons.org/publicdomain/ zero/1.0/) applies to the data made available in this article, unless otherwise stated in a credit line to the data. 
epidemiologic model-based estimates that account for underreporting of infections and deaths in India for wave 1 . We then proceed to compute, compare and combine wave 1 with wave 2 IFR estimates.

\section{Methods}

\section{Synthesizing evidence from seroprevalence studies}

We review available seroprevalence results that vary across states and specifically across rural versus urban areas. Whereas in many major metros and slum areas the seroprevalences were reported to be more than $50 \%$, in rural areas there is a wide variation (Table 1 ). The latest national serosurvey (from 17 December 2020 to 8 January 2021) reports $21.4 \%$ of all Indians above age 18 have antibodies present that indicate past SARS-CoV-2 infection [2]. Since approximately $59 \%$ [3] of India's 1.36 billion citizens are above age 18 and 10.45 million infections were reported as of 8 January 2021, this points to approximately 172.47 million infections, with an implied underreporting factor of $16.5(172.47 / 10.45)$. In other words, only $6 \%$ of India's COVID-19 infections are reported, while $94 \%$ remained undetected or unreported. We use this estimated number of infections to calculate the IFR. Regional studies based on crematorium data and counting obituaries in India have suggested an underreporting factor in the range of 2 to 5 for COVIDdeaths; this is at best ad hoc and anecdotal in nature and no rigorous quantification of missing death numbers is currently available [4].

\section{Model-based estimates}

Using a compartmental epidemiologic model (as explained in the Supplementary Methods) with a compartment for unascertained cases and deaths after accounting for the false negative rates of RT-PCR and rapid antigen tests used in India [5] we estimate the national and state-level IFR in India by inferring underreporting factors for cases and deaths. We assume that the estimated total infections (deaths) are comprised of reported and unreported infections (deaths). The model divides the population into ten disjoint compartments: S (Susceptible), E (Exposed), T (Tested), U (Untested), P (Tested positive), F (Tested False Negative), RR (Reported Recovered), RU (Unreported Recovered), DR (Reported Deaths) and DU (Unreported Deaths), as described in Additional file 1: Figure S1. A set of nine differential equations govern the transmission dynamics, which are approximated by means of discrete recurrence relations. For any compartment $X$, the instantaneous rate of change at time $t$ (given by $\frac{d X}{d t}$ ) is approximated by the difference of counts in that specific compartment on the $(t+1)$ th day and the $(t)$ th day, i.e., say $X(t+1)-X(t)$. Parameters are estimated using Bayesian techniques by generating samples from the posterior distribution using a Metropolis-Hastings algorithm with Gaussian proposal density, with $95 \%$ credible intervals (CrI) to quantify uncertainty of the estimates. Additional file 1: Table T4 presents an overview of the parameter descriptions and settings for this model.

\section{Comparing and combining waves 1 and $\mathbf{2}$}

Due to the stress on the healthcare and reporting infrastructure, the fatality and underreporting processes were very different across the two waves. Thus, we consider two separate phases of the pandemic, with wave 1 from April 1, 2020-January 31, 2021 and wave 2 starting on February 1, 2021. This definition is artificial and is guided by the fact that the national effective reproduction number $\left(\mathrm{R}_{\text {eff }}\right)$ crossed unity for the first time in 2021 on February 14 and we allow a two-week incubation period before that date. Using daily time series of case, death and recovery counts we compare fatality rates and underreporting factors associated with the two time periods using the compartmental models. Further, using observed data from the two waves and the model-based underreporting factor estimates, we compute cumulative case and death counts for the total duration of waves 1 and 2 . We multiply the wave-specific cumulative counts with relevant underreporting factors and sum over both waves to get combined counts of cases and deaths. The estimated numbers of cumulative deaths and infections provide us with a combined IFR estimate for India as of May 15.

\section{Results}

IFR estimates for wave 1 using seroprevalence surveys

The observed case fatality rate (CFR) in India is low. With 154,428 deaths and 10.76 million cases reported as of January 31, 2021 the estimated CFR for wave 1 is $1.435 \%$ (95\% confidence interval $1.428-1.442 \%$ ) [1]. The estimated number of infections from the January seroprevalence survey imply an approximate infection fatality rate of $0.09 \%$ (i.e. $154,428 / 172.47 \mathrm{M}$ ). The anecdotal underreporting factor for deaths (in the range of 2-5) implies an ad hoc estimate of IFR in the range of $0.19-0.45 \%$.

\section{Estimates from epidemiological models}

For wave 1 our estimate for the national $I_{1 F R}$ (observed cumulative deaths/estimated cumulative total infections) is $0.129 \%$ (95\% CrI $0.125-0.134 \%$ ) and $\mathrm{IFR}_{2}$ (estimated total cumulative deaths/estimated total cumulative infections) is $0.461 \%$ (95\% 
Table 1 Summary of results from various serological surveys conducted in India during 2020-21

Part A: State-level results from serological surveys conducted by the Indian Council of Medical Research in 2020-21

\begin{tabular}{|c|c|c|c|c|c|c|c|}
\hline \multirow[t]{2}{*}{ State $^{a}$} & \multirow{2}{*}{ 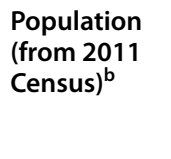 } & \multicolumn{2}{|c|}{$\begin{array}{l}\text { Serosurvey } I^{C} \\
\text { (May-June 2020) }\end{array}$} & \multicolumn{2}{|c|}{$\begin{array}{l}\text { Serosurvey } I^{\mathrm{d}} \\
\text { (August-September 2020) }\end{array}$} & \multirow{2}{*}{$\begin{array}{l}\text { Observed } \\
\text { cumulative cases } \\
\text { February } 7^{\mathrm{e}} \\
\text { (per million) }\end{array}$} & \multirow{2}{*}{$\begin{array}{l}\text { Observed } \\
\text { cumulative deaths } \\
\text { February } 7^{\mathrm{e}} \\
\text { (per million) }\end{array}$} \\
\hline & & $\begin{array}{l}\text { \# of people } \\
\text { tested }\end{array}$ & $\begin{array}{l}\text { \# of positive } \\
\text { samples (\%) }\end{array}$ & $\begin{array}{l}\text { \# of people } \\
\text { tested }\end{array}$ & $\begin{array}{l}\text { \# of positive } \\
\text { samples (\%) }\end{array}$ & & \\
\hline Maharashtra & $112,374,333$ & 2385 & $19(0.80)$ & 2681 & $348(12.98)$ & $18,189.84$ & 456.6 \\
\hline Kerala & $33,406,061$ & 1193 & $4(0.34)$ & 1282 & $11(0.86)$ & $28,989.92$ & 115.79 \\
\hline Karnataka & $61,095,297$ & 1199 & $3(0.25)$ & 1287 & $186(14.45)$ & $15,427.01$ & 200.28 \\
\hline Andhra Pradesh & $49,577,103$ & 1192 & $8(0.67)$ & 1245 & 352 (28.27) & $17,920.03$ & 144.4 \\
\hline Tamil Nadu & $72,147,030$ & 1200 & $16(1.34)$ & 1259 & 207 (16.44) & $11,667.8$ & 171.64 \\
\hline Uttar Pradesh & $199,812,341$ & 3616 & $15(0.42)$ & 3628 & $226(6.23)$ & 3009.75 & 43.48 \\
\hline West Bengal & $91,276,115$ & 2000 & $22(1.10)$ & 2097 & $219(10.44)$ & 6259.81 & 111.83 \\
\hline Odisha & $41,974,219$ & 1202 & $7(0.58)$ & 1223 & $294(24.04)$ & 7995.86 & 46.74 \\
\hline Rajasthan & $68,548,437$ & 1188 & $8(0.67)$ & 1212 & $27(2.23)$ & 4641.87 & 40.44 \\
\hline Chattisgarh & $25,545,198$ & 1210 & $4(0.33)$ & 1199 & $34(2.84)$ & $12,038.47$ & 146.45 \\
\hline India & $1,210,193,422$ & 28,000 & $156(0.56)$ & 29,082 & $3135(10.8)$ & 9027.74 & 128.77 \\
\hline
\end{tabular}

Part B: Results from some other serological surveys conducted in India in 2020-21

\begin{tabular}{|c|c|c|c|c|}
\hline Region & Study setting & Study period & \# of people tested & $\%$ of positive samples \\
\hline Delhi (Round 1$)^{f}$ & Urban & June-July, 2020 & 21,387 & 22.9 \\
\hline Delhi (Round 2) ${ }^{g}$ & Urban & August $1-7,2020$ & 15,046 & 28.4 \\
\hline Delhi (Round 3) ${ }^{g}$ & Urban & September 1-7, 2020 & 17,049 & 24.1 \\
\hline Delhi (Round 4) ${ }^{g}$ & Urban & October 15-21, 2020 & 15,015 & 24.7 \\
\hline Delhi (Round 5) ${ }^{h}$ & Urban & January, 2021 & 28,000 & 56.1 \\
\hline Tamil Nadu'i & Rural and Urban & October-November, 2020 & 26,640 & $\begin{array}{l}26.9 \text { (rural areas) } \\
36.9 \text { (urban areas) }\end{array}$ \\
\hline Mumbai (Round 1) & Urban & First half of July, 2020 & $\begin{array}{l}4234 \text { (slum areas) } \\
2702 \text { (non-slum areas) }\end{array}$ & $\begin{array}{l}57.0 \text { (slum areas) } \\
16.0 \text { (non-slum areas) }\end{array}$ \\
\hline Mumbai (Round 2) ${ }^{k}$ & Urban & Last half of August, 2020 & $\begin{array}{l}3024 \text { (slum areas) } \\
2176 \text { (non-slum areas) }\end{array}$ & $\begin{array}{l}45.2 \text { (slum areas) } \\
17.1 \text { (non-slum areas) }\end{array}$ \\
\hline Punel & Urban & July 20-August 5, 2020 & 1659 & 51.3 \\
\hline Chennai (Round 1) ${ }^{c}$ & Urban & July 17-28, 2020 & 12,405 & 18.4 \\
\hline Chennai (Round 2) ${ }^{c}$ & Urban & October 8-15, 2020 & 6366 & 30.1 \\
\hline Indore ${ }^{d}$ & Urban & August 11-23, 2020 & 7100 & 7.75 \\
\hline Karnataka $^{\mathrm{m}}$ & Rural and urban & June 15-August 29, 2020 & 15,624 & $\begin{array}{l}44.1 \text { (rural areas) } \\
53.8 \text { (urban areas) }\end{array}$ \\
\hline Jammu and Kashmir ${ }^{c}$ & Rural and urban & October, 2020 & 6230 & 38.8 \\
\hline India ${ }^{n}$ & Rural and urban & $\begin{array}{l}\text { December 17, 2020-January 8, } 2021 \\
\text { (Serosurvey III) }\end{array}$ & $\begin{array}{l}28,589 \text { (general population) } \\
7171 \text { (healthcare workers) }\end{array}$ & $\begin{array}{l}21.4 \text { (adults) } \\
25.3 \text { (children } \geq 10 \text { years) } \\
25.7 \text { (healthcare workers) }\end{array}$ \\
\hline
\end{tabular}

\footnotetext{
${ }^{a}$ The first ten states with maximum cumulative COVID-19 cases (as of 31 January 2021) are included in this table
}

b Information sourced from Wikipedia. (https://en.wikipedia.org/wiki/List_of_states_and_union_territories_of_India_by_population)

'The first national serosurvey conducted by the Indian Council of Medical Research (ICMR) began on May 11 and ended on June 4, 2020. A randomly sampled, community-based survey was conducted in 700 villages/wards, selected from the 70 districts of 21 chosen states of India, categorized into four strata based on the incidence of reported COVID-19 cases. Four hundred adults per district were enrolled from 10 clusters with one adult per household. A total of 28,000 adults were enrolled in the survey (Murhekar, Manoj V., et al. "Prevalence of SARS-CoV-2 infection in India: Findings from the national serosurvey, May-June 2020." Indian Journal of Medical Research 152.1 (2020): 48. https://doi.org/10.4103/ijmr.IJMR_3290_20)

d The second national serosurvey conducted by the ICMR began on from August 18 and ended on September 20, 2020. A strata-based sampling design similar to that of the first serosurvey (see (b) above) was used. A total of 29,082 individuals aged 10 years or older were enrolled in the survey. (Murhekar, Manoj V., et al. "SARS-CoV-2 antibody seroprevalence in India, August-September, 2020: findings from the second nationwide household serosurvey." The Lancet Global Health (2021). https://doi. org/10.1016/S2214-109X(20)30544-1)

${ }^{e}$ As of February 7, 2021. Information sourced from Coronavirus Outbreak In India-COVID-19 tracker (www.covid19india.org)

${ }^{f}$ Data from media reports (The Hindu. Published online July 22,2020. https://www.thehindu.com/news/cities/Delhi/percentage-of-people-with-antibodies-high/artic le32156162.ece) 
Table 1 (continued)

\begin{abstract}
${ }^{9}$ Data from a preprint on repeated, cross-sectional, multi-stage sampling serosurvey conducted from all districts and wards of Delhi, with two-stage allocation proportional to population size. (Sharma, Nandini, et al. "The seroprevalence and trends of SARS-CoV-2 in Delhi, India: A repeated population-based seroepidemiological study". medRxiv (2021). https://doi.org/10.1101/2020.12.13.20248123)

${ }^{h}$ Data from media reports (Hindustan Times. Published online February 02, 2021. https://www.hindustantimes.com/cities/delhi-news/delhis-5th-sero-survey-over-56people-have-antibodies-against-covid19-101612264534349.html)

' Data from a preprint on a population-representative serological survey conducted in all districts of Tamil Nadu, India in October-November 2020. (Malani, Anup, et al. "SARS-CoV-2 Seroprevalence in Tamil Nadu in October-November 2020." medRxiv (2021). https://doi.org/10.1101/2021.02.03.21250949)

j Data collected by a consortium of government organisations (NITI Aayog and Municipal Corporation of Greater Mumbai) and research institutes (Tata Institute of Fundamental Research and IDFC Institute) (https://www.tifr.res.in/TSN/article/Mumbai-Serosurvey\%20Technical\%20report-NITI.pdf)

${ }^{k}$ Data collected by a consortium of government organisations (NITI Aayog and Municipal Corporation of Greater Mumbai) and research institutes (Tata Institute of Fundamental Research and IDFC Institute) (https://www.tifr.res.in/TSN/article/Mumbai-Serosurvey\%20Technical\%20report-NITI_BMC-Round-2\%20for\%20TIFR\% 20website.pdf)

' Data from a preprint on multi-stage cluster random sampling of participants recruited from Pune sub-wards classified as high incidence settings for a serosurvey. (Ghose, Aurnab, et al. "Community prevalence of antibodies to SARS-CoV-2 and correlates of protective immunity in an Indian metropolitan city". medRxiv (2021). https://doi.org/10.1101/2020.11.17.20228155)

${ }^{m}$ Data from a research letter on a population-representative serological survey conducted in all districts of Karnataka, India in June 15-August 292020 (Mohanan M, Malani A, Krishnan K, Acharya A. Prevalence of SARS-CoV-2 in Karnataka, India. JAMA. Published online February 04, 2021. https://doi.org/10.1001/jama.2021.0332)

${ }^{n}$ Data from media reports (PTI. Published online February 04, 2021. https://www.ndtv.com/india-news/over-21-of-indias-population-may-have-had-covid-19-showssero-survey-2363166)
\end{abstract}

CrI $0.455-0.468 \%)$ with an underreporting factor for cases estimated at $11.11(95 \% \mathrm{CrI} 10.71-11.47)$ and for deaths at 3.56 (95\% CrI 3.48-3.64). These modelbased estimates in wave 1 are largely consistent with the estimates from the latest and third nationwide seroprevalence study.

In wave 2 , using the same model we see a stark contrast with wave 1 , with case and death underreporting factor estimates escalate to 26.73 (95\% CrI 24.2628.81) and 5.77 (95\% CrI 5.34-6.15) respectively, leading to $\mathrm{IFR}_{1}$ estimate of $0.032 \%$ (95\% CrI $0.029-0.035 \%$ ) and $\mathrm{IFR}_{2}$ estimate of $0.183 \%$ (95\% CrI $0.18-0.186 \%$ ). This pattern is consistent with wave 2 CFR being estimated at $0.845 \%$ (95\% CrI $0.840-0.849 \%$ ), $59 \%$ of wave 1 estimate.

Figure 1 shows underreporting factors and estimated infections and deaths in waves 1 and 2 for India while Fig. 2 highlights state-level variations in IFR $_{1}$, IFR $_{2}$, CFR for waves 1 and 2 for 20 states in India with large case/death counts.

\section{Combining waves 1 and 2}

The composite CFR as of May 15 stands at $1.1 \%$. The estimate for total (reported + unreported) cumulative case count for waves 1 and 2 combined is 491.73 (95\% CrI 453.03-524.56) million, while the estimated number of total (reported + unreported) deaths is 1216.35 (95\% CrI 1154.21-1272.70) thousand. This leads to a combined IFR ${ }_{1}$ estimate of $0.06 \%$ and IFR $_{2}$ estimate of $0.24 \%$. Detailed numerical estimates of underreporting factors across states for waves 1 and 2 are presented in Additional file 1: Tables T1, T2 and T3 and Additional file 1: Figures S2 and S3.

\section{Discussion}

Despite accounting for underreported deaths, the large number of asymptomatic/undetected infections (more than $90 \%$ by any calculation) indicate a lower IFR in India in comparison with other Western countries. A meta-analysis across the world places the pooled mean of IFRs at $0.68 \%$ (95\% CI: $0.53-0.82 \%$ ) [6], while another meta-analysis places the median at $0.27 \%$ [7] (with a range of $0-1.63 \%$ ). Seroprevalence surveys and epidemiologic models qualitatively agree on the estimated IFR for India for wave 1. Up to date serosurvey and excess death/mortality data are needed to validate wave 2 and combined estimates. The estimated number of total infections as of May 15 suggests roughly $36 \%$ of Indians have an active or past infection, a number that will need to be verified with synchronous sero-surveys.

The current reduction in fatality rates in wave 2 that we notice could be primarily due to two reasons, one is that we do not have the same length of follow-up period and complete data on the decay phase of wave 2 curve. The second could be the different age composition of the infected populations in the two waves; it has been reported that the younger population got infected in larger numbers in wave 2 and they have lower risk of COVID-19 mortality. A fraction of the older population (aged $65+$ years) also got vaccinated during wave 2 . However, this hypothesis about reduced fatality rates in wave 2 cannot be verified without more granular, age-sex stratified nationwide time-series data on case and death counts, which is currently unavailable. 


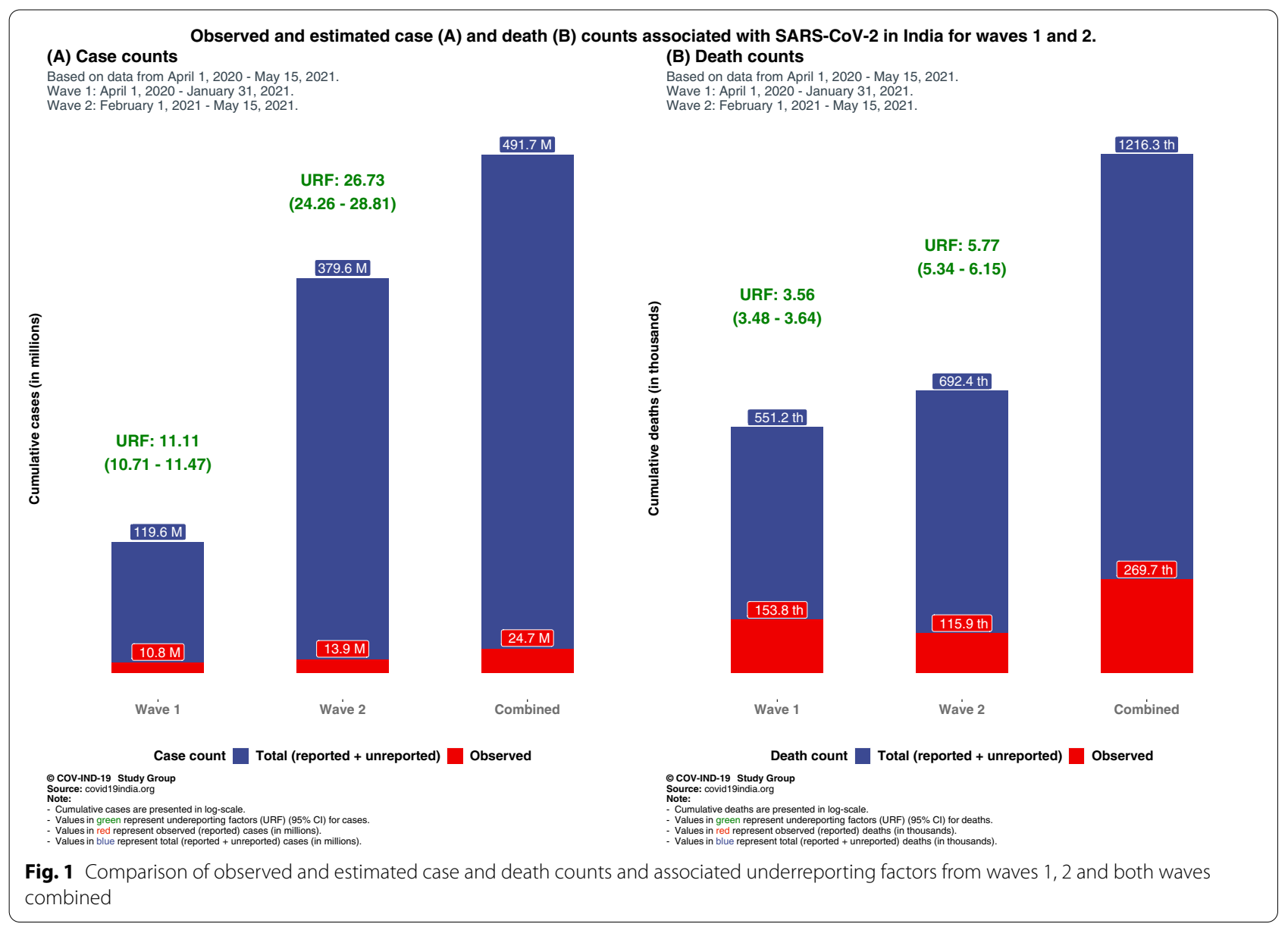

\section{Limitations}

We do not have a rigorous way to validate the extent of underreporting of deaths. An excess death calculation based on historical mortality data is infeasible at this point due to absence of all-cause-mortality data in the last three years from India. India has a very young population with only $6.4 \%$ in age group $65+$ (compared to the US where this proportion is 16.5\%) so a comparison of overall IFR between India and say the US is not fair, and only age-specific IFRs should be calculated and compared when more data become available. We do recognize that wave 2 information is appreciably incomplete, and the estimates will change as we have more complete information on deaths. For example, while our wave 2 analysis period ended on May 15, the highest daily number of deaths (4529 daily new deaths) were reported shortly after on May 18. Thus, our analysis presents an updated but incomplete picture of wave 2 .

\section{Abbreviations}

CFR: Case fatality rate; Cl: Confidence interval; Crl: Credible interval; IFR: Infection fatality rate; RT-PCR: Real time reverse transcript polymerase chain 


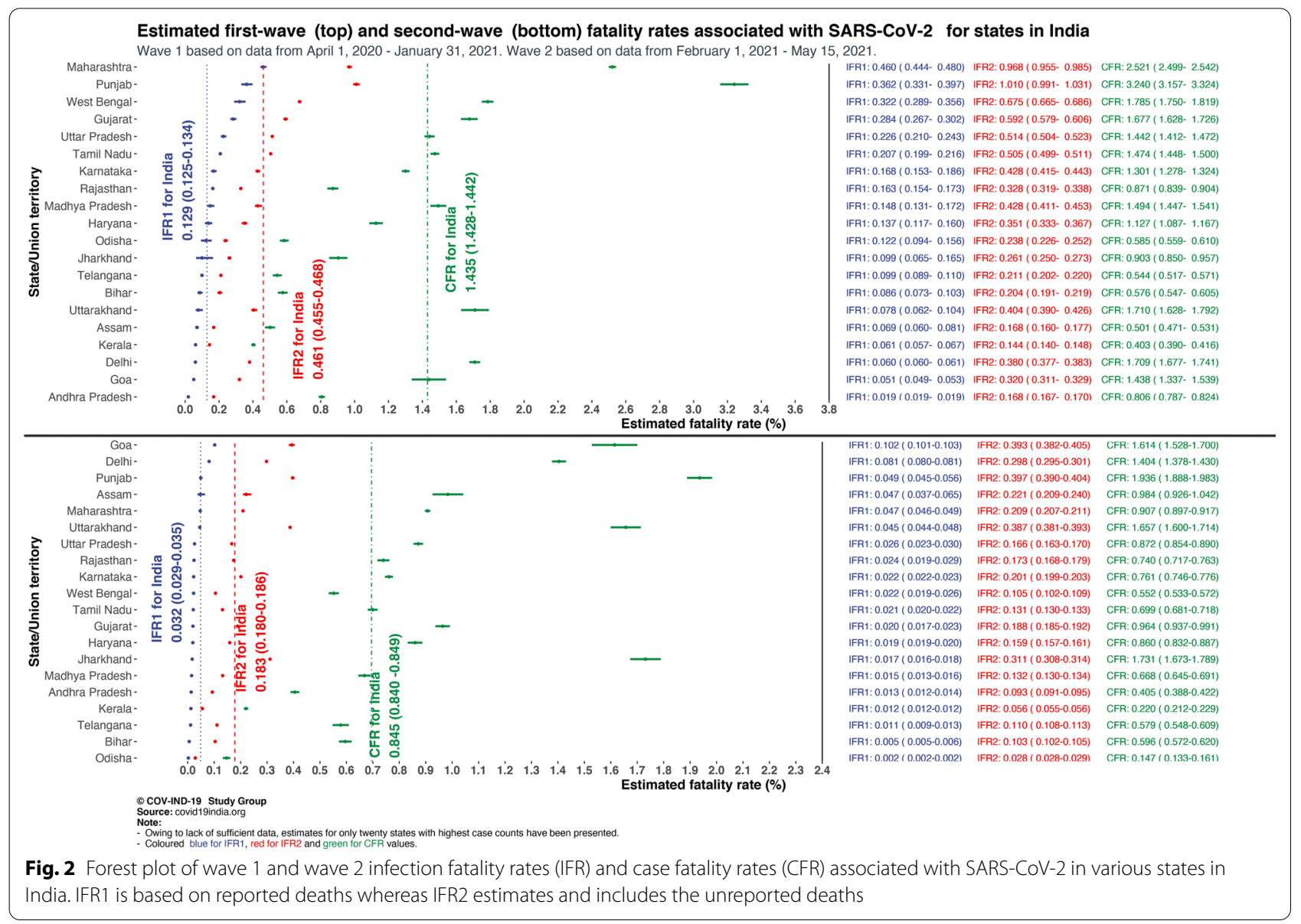

reaction; SEIR: Susceptible-exposed-infected-recovered; URF: Underreporting Factor.

\section{Supplementary Information}

The online version contains supplementary material available at https://doi. org/10.1186/s13104-021-05652-2.

Additional file 1: Figure S1. Schematic diagram for the SEIR-fansy model with imperfect testing and misclassification. Figure S2. Estimated first wave underreporting factors for cases and deaths associated with SARSCoV-2 for states in India. Figure S3. Estimated first wave underreporting factors for cases and deaths associated with SARS-CoV-2 for states in India. Table T1. Summary of the different metrics for the states and the nation for wave 1, on 31st January, 2021. Table T2. Summary of the different metrics for the states and the nation for wave 2, on 15th May, 2021. Table T3. Summary of the different metrics for the states and the nation for waves 1 and 2 combined, on 15th May, 2021. Table T4. Parameter values and descriptions for the SEIRfansy model.

\section{Acknowledgements}

The authors are grateful for the computational resources available to them via the advanced research computing center at the University of Michigan.

\section{Authors' contributions}

SP created the initial draft, conducted the literature review and collaborated on the analysis. RK and RB created the R package SEIR-fansy and implemented the epidemiologic models. DB and MK collaborated on analysing data from the second wave. DR helped create and modify the final draft and address issues raised by the review panel. BM conceived the project, planned the analysis and wrote the draft of the paper. All authors read, reviewed, edited and approved the manuscript for submission.

\section{Funding}

The research was supported by an internal pilot grant at the University of Michigan, awarded by the Michigan Institute of Data Science (MIDAS).

\section{Availability of data and materials}

All data are publicly available at covid19india.org. We used reported daily case, death and recovery counts for India and its states and union territories from April 1, 2020 to May 15, 2021. The statistical package SEIR-Fansy developed by the authors is available at covind19.org.

\section{Declarations}

\section{Ethics approval and consent to participate}

Not applicable. The analysis is based on publicly available completely deidentified aggregate counts. The study is exempt from IRB review as no patient participation or contact is involved.

\section{Consent for publication}

Not applicable.

\section{Competing interests}

There are no conflicts of interest perceived or declared by any of the authors. 


\section{Author details}

'Department of Biostatistics, University of Michigan, Ann Arbor, Ml 48109, USA. ${ }^{2}$ Indian Statistical Institute, Kolkata, West Bengal 700108, India. ${ }^{3}$ Department of Epidemiology, Johns Hopkins Bloomberg School of Public Health, Baltimore, MD 21205, USA. ${ }^{4}$ Department of Biostatistics, Johns Hopkins Bloomberg School of Public Health, Baltimore, MD 21205, USA. ${ }^{5}$ Center for Precision Health Data Science, University of Michigan, Ann Arbor, MI 48109, USA. ${ }^{6}$ Department of Epidemiology, School of Public Health, University of Michigan, Ann Arbor, MI 48109, USA.

Received: 13 March 2021 Accepted: 9 June 2021

Published online: 08 July 2021

\section{References}

1. COVIDIndia.org. COVID-19 Tracker Updates for India for State-wise and District-wise data. Published 2020. https://covidindia.org. Accessed 21 May 2020

2. Press Trust of India. Over $21 \%$ of India's population may have had COVID19, shows sero survey. Published February 4, 2021. https://www.ndtv. com/india-news/over-21-of-indias-population-may-have-had-covid-19shows-sero-survey-2363166
3. Wikipedia. Demographics of India: structure of the population. https:// en.wikipedia.org/wiki/Demographics_of_India\#tStructure_of_the_popul ation. Accessed 20 Feb 2021

4. The Wire. COVID-19: Cremation, burial records suggest Delhi's death toll is over twice the official figure. Published May 27, 2020. https://thewire.in/ government/delhis-covid-19-deaths-data. Accessed 20 Feb 2021

5. Bhaduri R, Kundu R, Purkayastha S, Kleinsasser M, Beesley $\sqcup$, Mukherjee B. Extending the Susceptible-Exposed-Infected-Removed (SEIR) model to handle the high false negative rate and symptom-based administration of COVID-19 diagnostic tests: SEIR-fansy. Epidemiology. 2020. https://doi. org/10.1101/2020.09.24.20200238.

6. Meyerowitz-Katz G, Merone L. A systematic review and meta-analysis of published research data on COVID-19 infection fatality rates. Int J Infect Dis. 2020;101:138-48. https://doi.org/10.1016/j.jij. 2020.09.1464.

7. Ioannidis JPA. Infection fatality rate of COVID-19 inferred from seroprevalence data. Bull World Health Organ. 2021;99(1):19-33F. https://doi.org/10. 2471/BLT.20.265892.

\section{Publisher's Note}

Springer Nature remains neutral with regard to jurisdictional claims in published maps and institutional affiliations.
Ready to submit your research? Choose BMC and benefit from:

- fast, convenient online submission

- thorough peer review by experienced researchers in your field

- rapid publication on acceptance

- support for research data, including large and complex data types

- gold Open Access which fosters wider collaboration and increased citations

- maximum visibility for your research: over $100 \mathrm{M}$ website views per year

At BMC, research is always in progress.

Learn more biomedcentral.com/submissions 